\title{
Construction of evaluation index system of The Countries' Sustainable Development Degree
}

\author{
Zhen Wang \\ North China Electric Power University, Baoding 071000, China
}

Keywords: The sustainable development; Clustering analysis; Redundancy; Completeness.

\begin{abstract}
The method of combining qualitative analysis and quantitative calculation is adopted to build evaluation index system of sustainable development for countries. To complete the indicators set, two steps are needed: Primary election and improvement of indicator set. Starting from the definition and the connotation of sustainable development, we get the principle of index selection and primary indexes based on it. Then we test the redundancy and completeness of index to perfect it.
\end{abstract}

\section{Introduction}

In 1987, led by Mrs Boulogne rand, world commission on environment and development (WCED) published a report "our common future". The report formally used the concept of sustainable development, pushing people to re-think about the traditional development model and pay attention to sustainable development .The report has been published nearly 30 years. In the 30 years, people have done a lot of research on sustainable development, and made a lot of achievements. The understanding of sustainable development is becoming more and more deeply. In short, sustainable development emphasizes coordinated development of social development, economic growth, resource\& environment and so on various aspects. But due to the reality sustainable development is a complicated system, involving every aspect of human society, to determine the selection of evaluation index becomes the difficulty of the sustainable development research.

Based on the above analysis, the paper takes the construction of Laos' sustainable development evaluation index system as an example, putting forward a new method of evaluation index selection, combining qualitative analysis and quantitative calculation ${ }^{[1]}$.Qualitative analysis is a process: First of all, we should fully understand the connotation of sustainable development. Based on this, the principles of indexes selection will be obtained. Finally, we can select indicators according to the principles. Quantitative calculation is a process based on the index redundancy and completeness inspection to make the index system more scientific and reasonable. Therefore, the construction of index system can be divided into two steps, the index set of primary and perfect.

\section{Primary index set}

\subsection{The definition and connotation of sustainable development}

In the report our common future, sustainable development is defined as a development mode which is not only meet the demand of modern people, but also without compromising the ability of future generations to meet their needs. It's a kind of long-term economic growth mode.

The connotation of the sustainable development includes the following several aspects:

Highlight the theme of development: Development and economic growth have a fundamental difference. Development is the social development, economic growth and resources and environment in the integration of complete phenomenon, not simply emphasis on GDP growth.

The sustainability of development: Human economic and social development can't go beyond the carrying capacity of resources and the environment;

The fairness of the human relations: During modern people' development, they should strive to make the development of future generations have the same opportunity. In the same generation, some person's development should not damage the interests of others.

Coordinate symbiosis of human and nature: Human beings must set a new standard of morality and value, learning to respect nature, protecting nature, and in harmony with nature. 


\subsection{Principle of the selection of national sustainable development indexes ${ }^{[3]}$}

In order to measure sustainable development level in different countries roundly, objectively and scientifically, the basic norms of statistics ought to be satisfied, In addition, the following principles should be followed

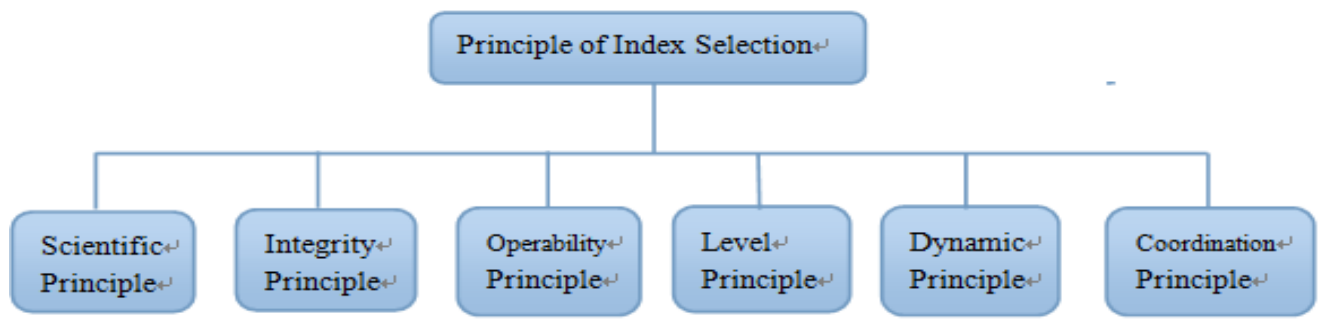

\subsection{The evaluation index of concrete}

Figure 1 Principles of Index Selection

Sustainable development system is subdivided into three subsystems: social development, economic growth and resource \& environment. Each subsystem will be reflected with a number of indicators.

Social development indexes. Population is the main part of the social activities, and is the only the element which has subjective initiative in the human development system. The aim of the social development is to improve people's living quality social justice. so social development indicators are from the population development, living standards, social justice and so on several aspects. Specific indicators shown in the following table.

Table 1 Social Development Indexes

\begin{tabular}{|c|c|c|}
\hline Secondary Indicators & Specific Indexes & Type \\
\hline \multirow{3}{*}{ Population Development $\left(C_{1}\right)$} & Population growth rate $\left(D_{1}\right)$ & 0 \\
\cline { 2 - 3 } & Population mortality $\left(D_{2}\right)$ & 0 \\
\hline \multirow{2}{*}{ Living Standard $\left(C_{2}\right)$} & Urbanization rate $\left(D_{3}\right)$ & 1 \\
\cline { 2 - 3 } & Life expectancy at birth, total $\left(D_{4}\right)$ & 1 \\
\cline { 2 - 3 } & Food production index $\left(D_{5}\right)$ & 1 \\
\hline \multirow{3}{*}{ Social Security $\left(C_{3}\right)$} & Health expenditure per capita $\left(D_{6}\right)$ & 1 \\
& Health expenditure, total $\left(D_{7}\right)$ & 1 \\
\cline { 2 - 3 } & School enrollment, tertiary $\left(D_{8}\right)$ & 1 \\
\hline
\end{tabular}

Note: 0 represents Cost Index, for these indicators, the smaller, and the better.

1 represents Efficiency Index, for these indicators, the bigger, the better.

Economic growth indexes. Economic growth is the foundation of a nation's sustainable development, which guarantee social development, resources and environment protection, sequential improvement of people's material and cultural life. Macroeconomic indicators reflect the development of national economy in general level. Industrial structure shows the country's stage of economic development. Therefore, Economic growth indicators mainly from two aspects of economic level and the economic structure, the specific indicators shown in the following table.

Table 2: Economic Growth Indexes

\begin{tabular}{|c|c|c|}
\hline Secondary Indicators & Specific Indexes & Type \\
\hline \multirow{3}{*}{ Economic Level $\left(C_{4}\right)$} & GDP Per Capita $\left(D_{10}\right)$ & 1 \\
\cline { 2 - 3 } & GDP Growth $\left(D_{11}\right)$ & 1 \\
\cline { 2 - 3 } & GDP $\left(D_{12}\right)$ & 1 \\
\hline \multirow{2}{*}{ Economic Structure $\left(C_{5}\right)$} & Services, etc., value added $\left(D_{13}\right)$ & 1 \\
\cline { 2 - 3 } & Industry, value added $\left(D_{14}\right)$ & 1 \\
\hline
\end{tabular}


Resources \& Environment Indexes. A country's resources \& environment is the foundation of its economic development. It consists of two aspects: per capita hold of resources\&environment quality. The indexes have been expressed in Table 3.

Table 3: Resources \& Environment Indexes

\begin{tabular}{|c|c|c|}
\hline Secondary Indicators & Specific Indexes & Type \\
\hline \multirow{2}{*}{ Resources of } & Arable land per person $\left(D_{15}\right)$ & 1 \\
\cline { 2 - 3 } Per Capital $\left(C_{6}\right)$ & Forest area $\left(D_{16}\right)$ & 1 \\
\cline { 2 - 3 } & Energy use per capita $\left(D_{17}\right)$ & 1 \\
\hline \multirow{2}{*}{$\begin{array}{c}\text { Environmental } \\
\text { Quality }\left(C_{7}\right)\end{array}$} & GEF benefits index for biodiversity $\left(D_{18}\right)$ & 1 \\
\cline { 2 - 3 } & The ratio of population with access to improved water $\left(D_{19}\right)$ & 1 \\
\hline
\end{tabular}

\section{The standardization of indicators}

Due to the use of different units of each index, we can't use the data which we get directly. To get the optimal value of the variable after transformation, we take the Standard 0-1 Transform ${ }^{[4]}$.

$$
D_{i} \text { : Efficiency Index, } b_{i j}=\frac{a_{i j}}{\max \left(a_{j}\right)} ; D_{i} \text { : Cost Index }, b_{i j}=1-\frac{a_{i j}}{\max \left(a_{j}\right)}
$$

\section{The improvement of the index set}

Scientific index system is the prerequisite to obtain the correct statistical analysis conclusion. The primary index system is based on people's subjective experience, and may not scientific. Therefore it must be carried out on scientific tests.

Indicators selected should be necessary and complete. Necessity is that index system of all indicators from whether is indispensable, with or without redundancy phenomenon. Because there is usually a certain degree of correlation between the evaluation indexes, make information index reflecting overlap. Integrity refers to the statistical index system after a necessity test whether has fully reflected the initial evaluation purpose and mission.

\subsection{The redundancy of the evaluation}

In terms of social development as an example, calculate the redundancy of the index set. By the method of cluster analysis and social development index clustering, if a strong correlation between indicators, illustrating the two indicators having similar foundation in the evaluation of the social development, and they should be together for a class. In each class, only one indicator can be kept and others are redundant.

Computational social development indicators between two correlation coefficient matrix, the correlation coefficient is greater than 0.7 indicators for a class, the results are as follows:

Table 4: Clustering results

\begin{tabular}{|c|c|c|c|c|c|c|c|c|c|}
\hline Classification & 1 & 2 & 3 & 4 & 5 & 6 & 7 & 8 & 9 \\
\hline indicators & $D 1$ & $D 2 D 4$ & $D 3$ & $D 5$ & $D 6$ & $D 7$ & $D 8$ & $D 9$ & D10 \\
\hline
\end{tabular}

The table 4 shows that D2 and D4 is classified as category. Only one can be kept, and there is a redundant indicators .

The proportion of redundant indicators: $R=\frac{1}{10} \times 100 \%=10 \%$

\subsection{Completeness evaluation}

Calculate the correlation coefficient matrix between specific indicators $D_{i}(i=1,2,3 \ldots 20)$ and secondary indicators $C_{j}(j=1,2,3 \ldots 7)$ matrix.

$$
\text { the effect of evaluation: } s_{j}=\frac{1}{20} \sum_{i=1}^{20} r_{i j} \quad j=1,2,3 \ldots 7
$$


Table 5: Calculation result of evaluation effect

\begin{tabular}{|c|c|c|c|c|c|c|}
\hline$S_{1}$ & $S_{2}$ & $S_{3}$ & $S_{4}$ & $S_{5}$ & $S_{6}$ & $S_{7}$ \\
\hline 0.32 & 0.29 & 0.25 & 0.19 & 0.18 & 0.22 & 0.2 \\
\hline
\end{tabular}

Set the threshold value is 0.2 . When $s_{j}>0.2$, it is said secondary indexes can be a good evaluation. Secondary indicators which can be a good evaluation: $s_{1} s_{2} s_{3} s_{6} s_{7}$ Secondary index coverage: $\mathrm{CP}=$ $\frac{5}{7} \times 100 \%=71.4 \%$

\section{Strengths}

During the process of the index of primary, in order to guarantee the rationality of the index selection, we deeply grasp the connotation of sustainable development. Based on this, the principles of index selection are obtained. Then select indicators according to the principle.In order to further improve the scientificity and rationality of the selected indicators set, primary indicators ought to be inspect on the redundancy and completeness.

\section{Reference}

[1]http://baike.sogou.com/v37114.htm

[2]Lv Tanhua. The Evaluation Index System of Su

stainable Development Research.2002.5.

[3]Teng Yunxian.Study on Index System of Regional Sustainable Development Based on Analytic Hierarchy Process Method.2009.5.

[4]Si Shoukui,Sun Xijing.Mathematical Modeling Algorithm and Application. National Defence Industry Press. 2014.2,345-350 